\title{
Research on Innovative Teaching Mode of Product Design Specialty in Flipped Classroom
}

\author{
Xueyue Long \\ Institute of Information Technology \\ Guilin University of Electronic Technology \\ Guilin, China
}

\begin{abstract}
Based on theories of flapped classrooms and online instruction, this article adopts an information-based teaching method to change the traditional one-way mode focusing on teaching into a modern two-way interactive mode aiming at communication, where teachers become promoters and instructors in learning. The mode is applied in the teaching of product design specialty, re-organizing the teaching system of product design specialty and building a teaching mode adapted to the network information environment and social demands, it builds a cooperative learning platform in the flipped classrooms, fosters the students' capabilities in collaboration, cooperation and communication and team spirits for win-win through cooperation, improve students skills in thinking and in knowledge acquisition.
\end{abstract}

Keywords-flipped classroom; product design specialty; innovation; teaching mode

\section{INTRODUCTION}

With the rapid development of science and technology, the ways for knowledge acquisition in the time of information has become fast and efficient, which is no longer subject to spaces, the core of this revolution is manifested in the mode of knowledge transmission. Flipped classroom is a new teaching mode where in an information environment, teachers deliver learning resources such as teaching videos, electronic lesson plans, courseware, curriculum resources library and so on through online platforms, and students watch teaching videos and learn after class, both teachers and students come together to complete homework, Q\&A, discussion and interactive communication in classrooms.

\section{CHARACTERISTICS OF THE FLIPPED CLASSROOM TEACHING}

Main reasons for the flipped classroom popular around include: First, teaching videos are short and pithy, each video is designed for a specific topic, much targeted, and easy to find; video length is controlled within the time range where students' attentions are centralized, owning functions as pause, playback and so on, and it is of self-control, good to help students in self-learning. Second, clear teaching information, the videos, abandoning factors not related to teaching, show knowledge points only. Third, rebuild the learning flow, information transmission is done by students before class,

Fund Project: Project Approved for Reforms of Higher Education and Teaching in Guanxi, Innovative Research and Practice of Product Design Specialty in Flipped Classroom, 2015JG416. teachers provide not only videos but also online instruction; the knowledge internalization is achieved in classrooms through interaction, teachers may grasp the difficulties of students in learning difficulties in advance, giving effective instruction in classrooms, meanwhile, the cooperation and exchange among students can better promote the knowledge internalization of students. "Fig. 1"

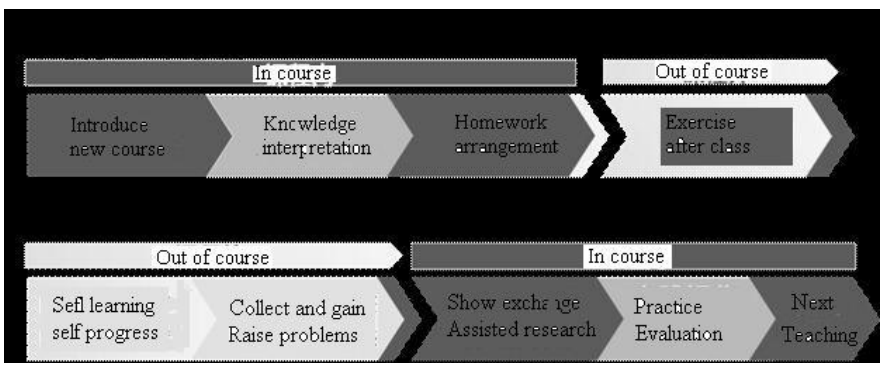

Fig. 1. Comparison between flipped classroom and traditional teaching

Outline for National Medium and Long-term Education Reform and Development (2010-2020) clearly points out, "Advocate a heuristic, explorative, discussing and participatory teaching and help students on how to learn; stimulate students' curiosities, cultivate students' interests and hobbies, and create a favorable environment for independent thinking, free exploration and innovation. The teaching philosophy of flipped classrooms has fully embodied the requirements related to the teaching reform stated in the Outline and opened a way for teachers to make innovations in the teaching reform.

\section{THE DEVElopment TREND OF MODERN EDUCATION Mode And Practical Problems in Product DESIGN SPECIALTY}

The development and popularization of network information technology have not only supported the traditional teaching mode but also brought a shock and challenge to it. In recent years, new teaching modes as Open Courseware, TED videos, micro-courses, which are famous around the world, are welcomed by the public, the new teaching approach provides innovative ideas in the course design, development, sharing and application. Based on this approach, the flipped classroom adjusts the traditional teaching methods to adapt to new 
teaching modes and development so as to foster talents meeting the needs of the society.

The product design specialty is a comprehensive discipline integrating art, engineering, physics and literature, which requires students to own extensive knowledge, high intensive practical abilities and innovation capabilities. The key for fostering such capabilities is to stimulate the subjective initiative of students, and enhance the desires for practice with the premise of independent study. Generally the teaching is divided into two stages namely knowledge transmission and knowledge internalization, in traditional teaching, it was focused only on the first step, namely information transmission in the learning process, which was considered as the most important part, that is, during the class teaching, the second step, namely knowledge internalization, was ignored, which was traditionally achieved after class where there were no any assistance provided. As a result, the classroom, which should be used for teacher-student interaction, peer collaboration and communication, was often occupied by teachers for knowledge transmission. The traditional teaching mode laid more emphasis on one-way knowledge transmission, in the lack of and even having no interaction or communication between teaching and learning. Finally students were forced to acquire knowledge and had no chances to participate or show themselves, to some extent, the students had no initiatives, the teachers had no interaction with students, and the students' capabilities in innovative thinking and organizational coordination were unable to fully exert.

\section{Status Quo At Home And AbroAd}

In 2000, J. WesleyBaker presented a paper, titled the "classroom flip": Using web course management tools to become the guide by the side, at the 11th international conference on college teaching and learning. In 2007, a chemistry teacher at Woodland Park High School in the American state of Colorado initiated a flipped teaching which was promoted to use in the American education. In 2011, with the development and popularization of the Internet, the flipped classroom was gradually popular in the United States.

Many schools have launched online video open courseware, excellent courses, micro-lecture, online three-dimensional textbooks, resource library and so on, which are in full swing at home. However, the teaching systems in most schools are still based on the traditional teaching mode, resulting in a relative isolation of the network resources, which are not fully integrated into the teaching systems and only used to support the teaching after class, failing to stimulate students to learn independently. Many professional disciplines in colleges, Guangxi Province, are also trying to establish a network of information teaching resources library, online excellent courses and online three-dimensional textbooks, but the construction of design specialty in independent schools goes slowly. The philosophy of flipped classroom can be used to establish an online design specialty teaching system, yet there are still no relevant researches in the independent schools in the region. It has been a problem worthy of thinking for instructors on how to use the advanced teaching idea, integrate network resources, how to closely combine online teaching, teaching way and classroom teaching and how to fully integrate network resources into the whole product design teaching system and exert its advantages.

\section{CONSTRUCTION OF FLIPPED CLASSROOM FOR THE PRODUCT DESIGN SPECIALTY}

A. Introduce the Teaching Philosophy of Flipped Classroom to the Product Design Teaching System, Take Specialty and Core Courses As Objects for the Construction, and Make Use of Network Information Resources to Re-Build the Product Design Specialty Teaching Mode

1) Guide by the flipped classroom and build 4 key points for the product design specialty teaching mode:

a) Switch roles of teachers: During the flipped classroom, teachers are switched from traditional disseminator to a promoter and instructor for teaching. Teachers are changed from the central focus of a lesson to the planner and pusher for classroom activities. But the change does not mean a pace moves from the stage to the backstage, but a movement of teachers from initial whoop and transmission to a high level leadership and instruction. During the flipped classrooms when students are in need of instruction before confusions, teachers are still the knowledge disseminators.

b) Re-divide class hours: To reducing the teaching time in classrooms is the second core feature of the flipped classroom. The teaching which occupied most time originally in class is transferred and made before class or after class, and the class time is mainly arranged by students. More learning activities are created for students in class, where proper teaching circumstances are formed to encourage students to collaborate in the activities and complete the learning tasks independently. The mode where students act as main parts in class activities can enhance students interests in learning, deepen their understanding of knowledge and intensify their initiative in learning and stimulate their creativity.

c) Switch roles of students: The flipped classroom teaching mode makes use of modern information technology in teaching and borrows Internet resources and platforms, where students may learn anytime and anywhere. Based on advanced teaching resources, students may conduct effective control on the learning and make targeted selections, who can select the content, time and capacity for learning as per the learning progress of their own and make self-adjustment if necessary. Through a given network platform, students can achieve the interaction with teachers and classmates, and the students' learning can be monitored by teachers via network technology, thus, the roles of students are switched. Therefore, the flipped classroom is a new classroom which breaks through the teaching barriers of traditional class teaching and expands the teaching and the learning to a wider space, where students become real leading characters in class.

d) Interaction stressed in learning: Based on the three points mentioned above, the roles of teachers and students have been switched, and the time division in class makes it easy for interaction between teachers and students, and the traditional teaching mode is weakened in class, with the 
further deepening of the flipped classroom, the class teaching will become a seminar where teachers communicate with students and present targeted instruction, participate in the student group discussion and guide the class for communication, collaboration and research.

During the flipped classroom teaching, generally students achieve learning and practice through groups. Freed from tedious knowledge transmission, teachers have more times to observe the interaction between students. Through the study groups, students can help and promote each other, forming a team spirit no longer relying only on the teachers in learning.

2) Teaching design and realization method in flipped classrooms: Teaching mode of flipped classroom as shown in "Fig. 2":

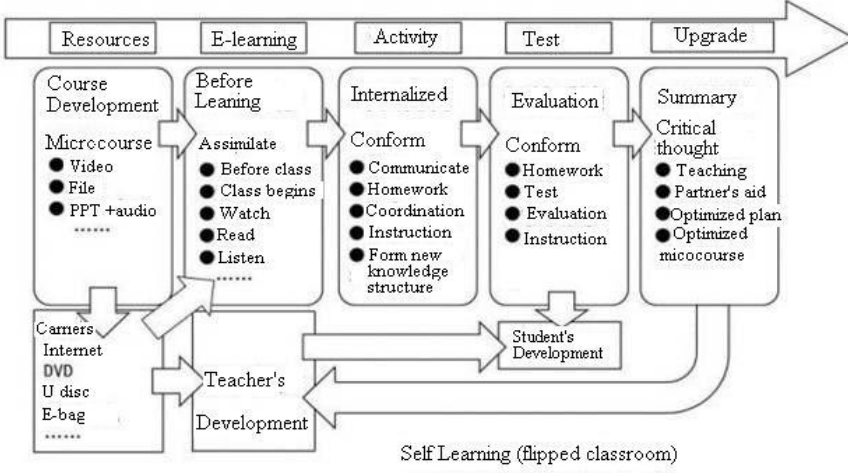

Fig. 2. Teaching Mode of Flipped Classrooms

First of all, teachers make a brief introduction to learning tasks, key points, difficulties, then deliver teaching resources recorded or downloaded to students and provide online instruction; then students will make self learning through video open courseware, network resources, 3-D curriculum textbooks according to the learning tasks or basic thought, achieving the self-acceptance of knowledge and finding problems if any; Next, it comes to the classroom, teachers create circumstances, and students offer problems to teachers for discussion, interaction and tests (practices) for verification, or carry out cooperative learning through work room, study group and network group so as to solve problems and realize the innovation and upgrade of knowledge. The teaching design is based on the combination of virtuality and reality, virtual network and real teaching environment are penetrated and complemented with each other, where students are not only promoted to fully exert the subjective initiative and innovation, but also well instructed, supported and supervised in the teaching.

3) Methods and ways for teaching quality control in flipped classroom: In order to achieve the flipped classrooms, it is very important for students to learn before class, and the efficient self-learning will push the class interaction to a higher level. "Fig. 3"

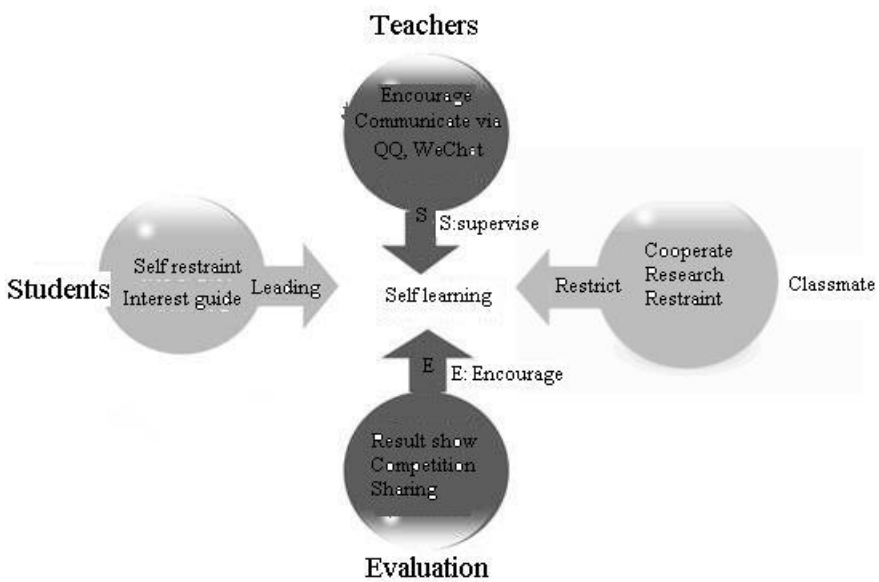

Fig. 3. Self learning quality control mode

a) Promote students for deep self learning before class, instead of the lesson preparation before class in traditional teaching: It will be difficult in some degree for students in the self-learning after class, to stimulate the power to learn independently is particularly important, therefore, through the interaction and communication in classrooms, work rooms and collaborative learning groups, students may raise problems and state programs so to fully demonstrate themselves, to whom appropriate incentives and competition should be offered in order to improve students' initiative, and create an emotional software environment for students' deep learning after class. Meanwhile, design and write highly integrated three-dimensional textbooks, video courseware, project-based collaborative research and network teaching platforms, and create a hardware environment necessary for students' deep learning after class.

Make use of advance online transmission tools (such as QQ group, WeChat, Fetion, etc.) for transmission of learning resources and information, and students may grasp the learning progress of their own and others at any time through network terminal equipment (such as computers, mobile phones, tablet $\mathrm{PC}$, etc) so as to achieve the real-time learning. The use of advanced electronic equipment in learning can not only expand the free spaces for learning but also improve the students' selflearning awareness.

b) Strengthen the efficient control and supervision in teaching: Through the construction of virtual teaching platforms, make use of QQ groups and WeChat to supervise the learning after class; organize and realize the self control and mutual restraint through the innovation base and collaborative learning groups, which help to achieve mutual cooperation and real-time learning control. Regard the classroom feedback and strengthen the interactive supervision in cooperative learning, clearly divide the tasks for cooperative learning, and advocate the results show in evaluation.

c) Carry out multi-channel evaluations: The flipped classroom does not reject examinations, it advocates an evaluation on comprehensive abilities, reduce the proportion 
of final examinations and increase the proportion of the interaction evaluation. Encourage students to carry out deep learning after class and find problems in learning. During the communication and interaction in classrooms, teachers can well grasp students' performance at ordinary times, raise scores in the interaction, stimulate students and promote the knowledge innovation.

Evaluation method: learning before class (20\%) + interaction in classrooms $(30 \%)+$ questions examination $(20 \%)$ + practice check $(30 \%)$.

\section{B. Construction of Teaching Platforms for Product Design Specialty on the Basis of Flipped Classroom}

Through the construction of virtual and real platforms, the teaching management design can be well operated under the ideal of flipped classroom, guaranteeing the teaching process and quality. Build the online innovative learning platform into an open and interactive platform spanning the time and region; and build the students' interactive work rooms as center and collaborative group as radius into a centralized and communication platform. "Fig. 4"

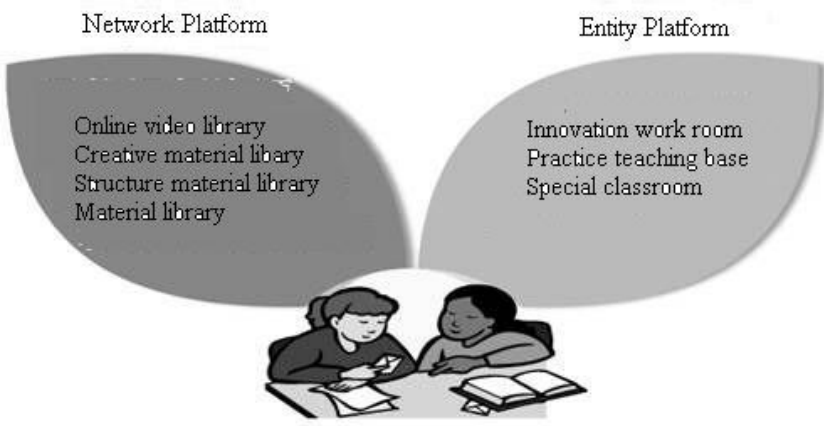

Fig. 4. Contents of network innovation platform and entity innovation platform

1) Construction of network innovation platform: Carry out the construction of network teaching platform aiming at the interaction between teachers and students, students and students, and teachers, based on which, implement and support the flipped classroom through the Internet.

Create a course group on the basis of the product design specialty, select Product Development Design, Product Design Skills and Design Basics as pilot courses, and explore the concrete implementation and evaluation methods for the flipped classroom in the teaching system of product design specialty. The above three courses are core courses for the product design specialty, requiring higher practical ability, which show basic knowledge of design, professional skills of designers and the comprehensive ability of design, and the course time runs through four years of the college, while the three courses form a complete product design process through mutual penetration and complement. The three courses are taken as pilots for a course group, on the basis of the flipped classroom, to achieve the exploration and practice of the teaching mode and methods for the product design specialty through online interaction, electronic courseware, microlecture and teaching videos.
2) Construction of entity innovation platform: Build an innovation practice work room for the product design specialty (collaborative learning group + classroom + projectbased learning group), and open a space for product specialty exhibition (work display + teaching resource sharing + information sharing).

\section{CONCLUSION}

Based on the theory of the flipped classroom teaching, make a summary of the teaching mode of the flipped classroom, according to philosophy of the flipped classroom, rebuild the teaching system of the product design specialty, and create a teaching mode of product design specialty meeting the network information environment and social demands. Expound how to create course resource library in the teaching reform, enhance the students' abilities to acquire effective resources in the information environment and to achieve the communication, exchange and assistance in cooperative learning and cultivate teachers' abilities of using information technologies. The innovation of this article mainly includes:

Introduce of the philosophy of the flipped classroom to the teaching of product design specialty to adapt to the network information environment and social demands, and fully exert students' subjective initiatives and enhance their abilities in self learning and innovation.

With the help of network and information, rationally exploit and collect existing resources, increase the students' time for self learning, stimulate students' enthusiasm and improve the teaching effect.

Construction of innovative learning platform with the combination of virtuality and reality can not only free students to improve students' abilities in self learning and innovation, but also supervise them to avoid "out-of control" so as to ensure the teaching quality.

Teaching tools, methods and modes all need practice and achieve continuous break-through on the basis of practice and accumulation. The flipped classroom is to verify the comprehensive abilities of teachers in grasping the classroom through teaching methods, to adopt special teaching methods to transmit professional knowledge to students will be a trend for teaches to explore in the teaching.

\section{REFERENCES}

[1] Wei Jiaxing, Exploring a New Teaching Mode for Industrial Design Specialty under Network Environment [J]. Science and Technology Information, 2015 (31)

[2] Strayer, J.F..The Effects of the Classroom Flip on the Learning Environment: A Comparison of Learning Activity in A Traditional Classroom and A Flip Classroom that Used an Intelligent Tutoring System[D]. Columbus : Doctor Degree Thesis of the Ohio State University, 2007.

[3] Pan Guoqing, Spiral Model and Realization of a Flipped Classroom [J]. E-Education Research, 2015, 10, 84 91

[4] Internet http://max.book1 18.com/html/2015/0301/12843284.shtm, 2015

[5] Shan Congkai, Wang Li, Development and Application of MicroLectures [J]. Distance Education in China, 2013, (12) 74 77. 
[6] Liu Jiliang, Wang Hongxi, MOOC-based Reform in College Teaching: Value and Limit [J]. Educational Research, 2015(08)

[7] Hu Jia, Lesson with Heterogeneous in the Flipped Classroom Teaching

[8] Zhang Lei, Wang Ying, Zhang Baohui, Study on Flipped Classroom Teaching Mode [J]. Distance Education Journal, 2012 (8) 